\title{
A CIDADE E A SUSTENTABILIDADE: investigação dos critérios e uma cidade verde e sustentável
}

\author{
Autor: LETICIA BARROSO \\ Programa de Pós-Graduação em Arquitetura e Urbanismo da Universidade Federal Fluminense (UFF) \\ Email: leticiabarroso@gmail.com
}

\begin{abstract}
RESUMO
O presente trabalho tem, como fio condutor, o tema sustentabilidade. Para tanto, visando investigar o conceito de sustentabilidade, elegemos o município de Sorocaba, cidade situada no interior do Estado de São Paulo, premiada em diversas categorias e que foi considerada uma das melhores cidades do Brasil. A hipótese inicial é que a elevação da cidade à categoria de cidade sustentável não expressa o que a população local entende por sustentabilidade. Buscamos identificar os indicadores e/ou temas que contribuíram para essas premiações e o seu reflexo na cidade e, de forma complementar, a percepção dos moradores a respeito dos assuntos abordados e seus posicionamentos sobre o que é uma cidade sustentável. O trabalho concluído apresenta resultados que confirmam a hipótese inicial, revelando, ainda, outros aspectos que merecem ser incorporados para se aferir uma cidade sustentável. Apresenta, ainda, diretrizes que devem guiar o planejamento ambiental com vistas à sustentabilidade.
\end{abstract}

Palavras chaves - sustentabilidade, indicadores, cidade, qualidade de vida.

\begin{abstract}
The aim was to investigate what the public understands by the concept 'sustainability'. With this in mind, Sorocaba, a town located in the interior of São Paulo State, was chosen for the purpose. The town has received several awards in various categories, even reaching the point of being considered one of the most sustainable in Brazil. The initial hypothesis is that reaching this category does not necessarily express residents' perception of what this means. Focus was on identifying indicators or themes that have contributed to these awards, as well as their impact on the town, and as a complementary measure, on residents' perceptions of the topics dealt with and their positions on what they consider a sustainable town to be. Finally results confirmed the initial hypothesis, besides revealing further concepts that deserve to be incorporated, as aids in gauging what really is a sustainable town. Furthermore, other guidelines are presented, which could be useful for conducting environmental planning with a view to sustainability.
\end{abstract}

Key-words - sustainability, indicators, town, quality of life. 


\section{INTRODUÇÃO}

Mas o que torna uma cidade sustentável? Segundo Acselrad (2001, p.49) "a noção de cidade sustentável instaura uma nova cena de enunciação, em que uma trama de múltiplos personagens e falas entrecruzadas reelabora as representações da cidade." Pensar cidades sustentáveis implica inserir questões ambientais, mas também incorporar as dimensões sociais, econômicas e culturais que vêm se consolidando por meio de princípios, métodos e ações.

Alem destes, ao se buscar a sustentabilidade da cidade, deve-se ater a dois importantes elementos: a justiça ambiental e a resiliência. $O$ primeiro remete à reflexão sobre a apropriação dos recursos ambientais e o modo de organização do espaço, na produção e reprodução da sociedade. A abordagem da justiça ambiental de Acselrad (2004) implica contrapor entre interesses, típicos. de abordagens tecnocráticas e economicistas. Cabe destacar que os danos ambientais atingem, na maioria das vezes, as populações mais vulneráveis, ou seja, enquanto algumas pessoas ganham com a degradação, outras são oneradas com os custos ambientais.

A Resiliência introduz uma nova abordagem para se lidar com a gestão das cidades e a fim de mantê-las em um estado contrário ao da vulnerabilidade. Isso significa desenvolver capacidades adaptativas das cidades a eventos adversos e a ameaças naturais.

Tornar-se resiliente impõe conhecer, com profundidade, a dimensão dos riscos, as vulnerabilidades dos sistemas e promover a gestão dos possíveis desastres. Vulnerabilidade, nesse sentido, é compreendida como uma forma de fragilidade ou de incapacidade de um sistema lidar com as adversidades.

Em nossa abordagem, consideramos a Cidade Sustentável aquela capaz de responder às adversidades, reduzir a desigualdade social, promover um ambiente seguro, com outros estilos de vida e a construir pactos para enfrentar os desafios.

Na busca por uma sustentabilidade urbana, diversos organismos governamentais e não governamentais se apoiaram em índices como uma forma de entender, classificar e garantir uma boa cidade de se viver. Para tanto, indicadores foram construídos para mensurar, avaliar, no sentido de orientar as políticas públicas para o alcance de uma cidade sustentável. Nesse sentido, escolhemos Sorocaba por ser uma cidade que vem sendo premiada em diversas categorias.

Sorocaba, na década de 2010 , foi proclamada, por meio do discurso oficial, como a cidade que promoveu a modernização da gestão pública em benefício da população, que ficou em $1^{\circ}$ lugar no Ranking Nacional de Transparência Pública, também como cidade empreendedora, por meio do Índice das Cidades Empreendedoras, do Instituto Empreender Endeavor.

E, mais recentemente, Sorocaba foi premiada em 10 lugar como cidade sustentável do Brasil, no Programa Cidades Sustentáveis, em 2014, e em 1ํ lugar no Estado de São Paulo no Programa do Município VerdeAzul, em 2013. Essas duas premiações e os dois programas serão contemplados em nosso estudo.

O painel acima descrito, à primeira vista, leva a crer que os programas governamentais contribuíram para a construção de uma cidade com qualidade de vida. Nossa pesquisa investigou, portanto, a partir de uma cidade brasileira, se essas premiações correspondem, de fato, a melhorias no ambiente urbano e, mais especificamente, no âmbito dos moradores que vivem nesse ambiente.

\section{A CIDADE E SEUS INDICADORES}

Esses Programas oferecem aos gestores municipais uma pauta com um conjunto de indicadores e metas, com as quais se pretende nortear o desenvolvimento das ações, para que o município seja certificado como "Município Verde" e "Cidade Sustentável". Enquanto o Programa Município VerdeAzul se reporta às questões ambientais, o Programa Cidade Sustentável contém as dimensões de âmbito social, ambiental, cultural e político.

O Projeto Estratégico Município Verde, lançado em 2007, pelo Governo do Estado de São Paulo, por meio da Secretaria de Estado do Meio Ambiente, com o objetivo de descentralizar a gestão ambiental e pautar a agenda municipal. Conta com dez Diretivas constituídas pelos seguintes temas: Esgoto Tratado, Resíduos Sólidos, Biodiversidade, Arborização Urbana, Educação Ambiental, Cidade Sustentável, Gestão das Águas, Qualidade do Ar, Estrutura Ambiental e Conselho Ambiental. Sorocaba aderiu ao Programa em 2008. Assim, os esforços se voltaram para o cumprimento das Diretivas.

Para receber a certificação do "Município VerdeAzul", o município deve executar as ações e comprová-las, conforme orientação do Programa, elaborar o Plano de Ação e obter nota superior a oitenta pontos. Ao final, o município recebe o Certificado Município VerdeAzul, emitido pela Secretaria de Estado do Meio Ambiente, que atesta o cumprimento das dez Diretivas Ambientais estabelecidas.

O Plano de Ação contém as informações a serem apresentadas pelo interlocutor que declara as ações planejadas e executadas pelo Município no cumprimento das Diretivas. Esse documento é composto por 
Diagnóstico, Plano de Metas, Arquivos e Relatório de Gestão Ambiental - RGA ${ }^{1}$ - informações que devem ser enviadas por meio digital, com documentos comprobatórios, tais como, leis, decretos, atas, fotos, certificados, entre outros.

Em função da exigência do PMVA, foram realizadas as seguintes ações: mapeamento das nascentes da cidade, Plano de Arborização Urbana, Plano da Mata Ciliar e outros Planos. Envolveu-se, nesse processo, o legislativo e o executivo para a elaboração e a aprovação de dispositivos legais na área ambiental, permitindo uma atuação mais consistente do município. Houve plantios e revitalização de parques da cidade. Além disso, houve a integração as diversas secretarias municipais, com o esforço de atingir as metas estabelecidas.

O Programa Cidades Sustentáveis tem como objetivo sensibilizar e mobilizar as cidades brasileiras para o desenvolvimento ambientalmente sustentável. Trata-se de uma Plataforma com uma agenda para a sustentabilidade das cidades, que aborda as diferentes áreas da gestão pública e incorpora, de maneira integrada, as dimensões social, ambiental, econômica, política e cultural. Em 2013, a cidade de Sorocaba aderiu ao Programa Cidade Sustentável. E, para os signatários da carta-compromisso, foi desenvolvido um sistema para o preenchimento do relatório dos 100 indicadores básicos.

O Programa Cidades Sustentáveis conta com doze eixos: (1) Bens Naturais; (2) Equidade, Justiça Social e Cultura de Paz; (3) Gestão local para Sustentabilidade; (4) Planejamento e Desenho Urbano; (5) Cultura para a Sustentabilidade; (6) Educação para a Sustentabilidade e Qualidade de Vida; (7) Economia Local, Dinâmica, Criativa e Sustentável; (8) Consumo Sustentável e Opção de Estilo de Vida; (9) Melhor Mobilidade e Menos Tráfego; (10) Ação Local para a Saúde; (11) Do Local para o Global; (12) Governança. Em 2014, Sorocaba ficou em 1ํ lugar no Programa Cidade Sustentável. Para essa classificação, foi apresentado o diagnóstico do município, um Plano de Metas e a divulgação desse Plano. Foi por conta da qualidade, confiabilidade, transparência, divulgação dos dados fornecidos, dados preenchidos e quantidade de novos indicadores cadastrados, que Sorocaba foi eleita como Cidade Sustentável em 2014. Além destes documentos, também foi elaborado o Plano de Metas de Sorocaba.

\section{A CIDADE E SUA HISTÓRIA}

Sorocaba, eixo econômico entre as regiões Norte, Nordeste e Sul, tornou-se um marco obrigatório para os tropeiros $^{2}$ no século XVIII, por volta de 1750 , devido a sua posição estratégica. Com o fluxo de tropeiros, desenvolveu-se, no povoado, a Feira de Muares, onde brasileiros de todos os Estados reuniam-se para comercializar animais

Com o declínio da atividade e, consequentemente, o fim das feiras, em 1880, iniciou-se, na região, o cultivo do café, que anunciava um novo ciclo econômico. A presença crescente das lavouras e o aumento da produção passaram a exigir um deslocamento mais ágil, já que o comércio se expandia para mercados cada vez mais distantes. Assim, em 1875, foi inaugurada a Estrada de Ferro Sorocabana (EFS). ${ }^{3}$

A linha férrea e a estação ferroviária foram grandes indutoras do crescimento da região, pois, perto delas, assentaram-se fábricas de tecidos e, consequentemente, foram construídas as vilas operárias, a norte e noroeste, em direção a São Paulo.

A primeira mancha urbana se desenvolveu ao redor da Estação Ferroviária, ou melhor, ao longo da linha férra, no sentido leste-oeste. Três elementos físicos foram condicionantes para a configuração espacial da cidade: o rio Sorocaba, que corta a cidade norte-sul; a Rodovia Raposo Tavares, que corta a cidade no extremo sul, no sentido leste-oeste; e a linha férrea, que corta o centro da cidade no sentido leste-oeste.

A cidade cresceu muito a partir da desconcentração industrial de São Paulo, na década de 1970. Isso a consolidou como polo industrial do Estado, e atualmente Sorocaba é um dos polos de desenvolvimento econômico do Estado e um dos pontos atrativo da região.

Sorocaba conta com 98,9\% de residentes na área urbana (IBGE, Censo Demográfico, 2010) e com uma população de 586.625 (IBGE, 2010). Localiza-se na região sudoeste do Estado de São Paulo, distante aproximadamente 95 quilômetros da capital, com uma área territorial de $449 \mathrm{Km}^{2}$.

A dinâmica da economia nacional, na primeira metade do século XX, deve-se à indústria voltada para produção de capital e de consumo. A indústria têxtil já vinha decaindo, quando, na década de 1990, a região passou a ser caracterizada por uma industrialização diversificada, com a presença de indústria de

\footnotetext{
${ }^{1}$ Relatório de Gestão Ambiental - RGA: consiste na síntese do Plano de Metas proposto.

${ }^{2}$ Tropeiro é aquele que conduz as tropas de muares, cavalos, entre as regiões de produção e os centros consumidores. Antes das estradas de ferro, o comércio de mercadoria era realizado pelos tropeiros.

${ }^{3}$ Atualmente o prédio abriga o Museu Ferroviário de Sorocaba, inaugurado em novembro de 1997 para preservar a história da antiga Estrada de Ferro Sorocabana (EFS).
} 
máquinas, siderurgia e metalurgia pesada, indústria automobilística, de autopeças, de equipamentos agrícolas, químicas, petroquímicas, indústrias farmacêuticas, de papel e celulose, de produção de cimento, de energia eólica, de eletrônica, de ferramentas, de telecomunicações, entre outras.

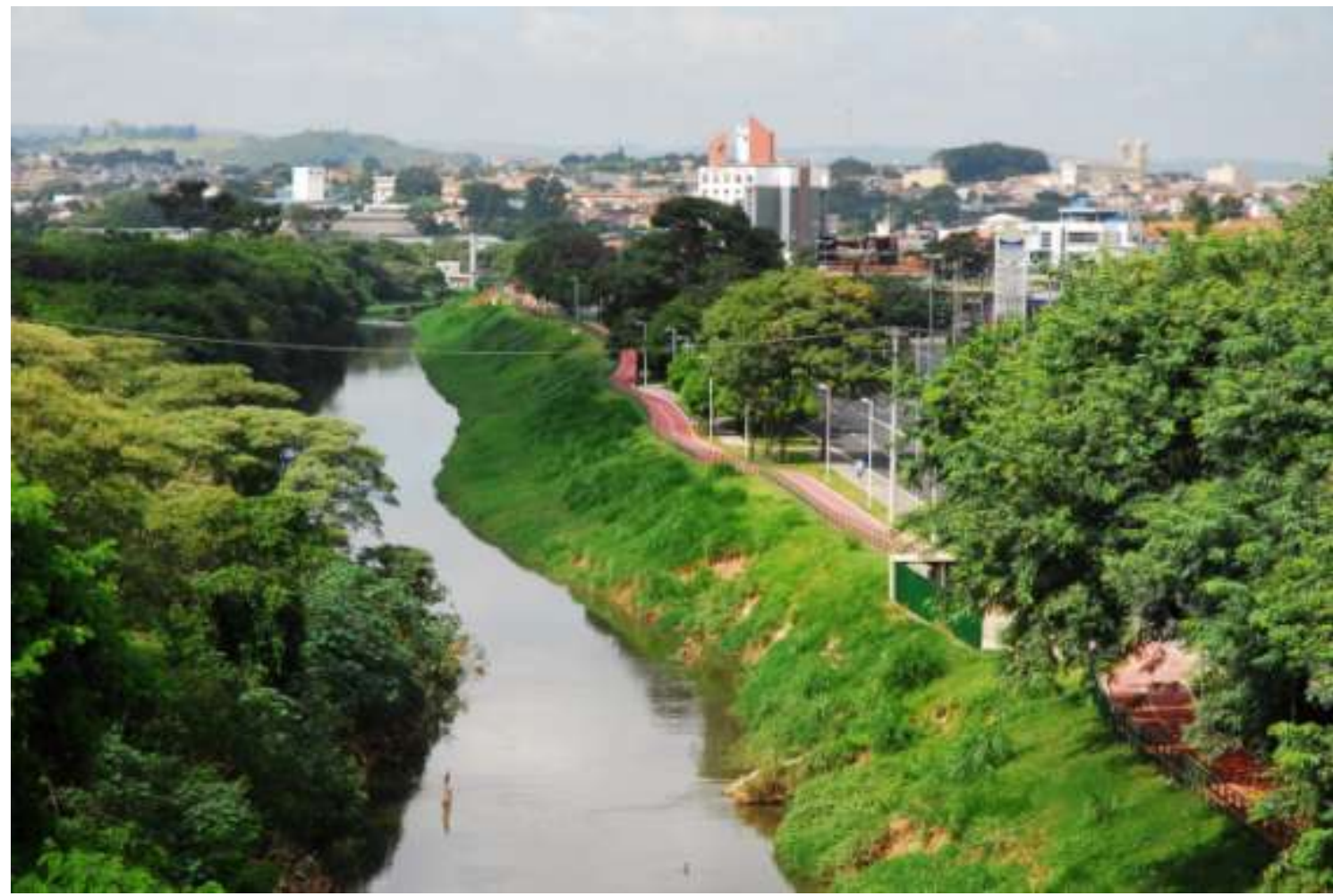

Foto 1 - Rio Sorocaba e Av. Dom Aguirre. Fonte. Acervo da Secretaria de comunicação, 2010

Não se pode deixar de registar que esses movimentos impactaram o ambiente da cidade. Sorocaba tem sido palco de grandes processos de transformações por conta da urbanização responsável, também, por alterar a cobertura vegetal da cidade e provocar devastação da Mata Atlântica e do Cerrado.

\section{METODOLOGIA}

O objetivo geral foi investigar, dentro de um quadro de condições sustentáveis possíveis, se as premiações refletem a realidade local e, em caso afirmativo, como isso acontece. Investigo, ainda, a relação entre os indicadores contemplados pelos Programas que elegeram Sorocaba como uma das melhores cidades para se viver e a percepção da população a respeito deles. Além disso, investigo os desejos da população no que se refere à promoção de uma cidade sustentável.

O referencial teórico deste trabalho está organizado segundo os conceitos e questões-chave da pesquisa. Com relação à produção do espaço, dentre as abordagens da geografia humana, destaca-se David Harvey (2006, 2014), Henri Lefebvre $(1996,2001)$, é a referência para a compreensão dos processos e das contradições sociais no espaço. Para o entendimento dos resultados das Conferências da Organização das Nações Unidas (ONU) e dos conceitos de desenvolvimento sustentável e de qualidade de vida e seus indicadores, apoio-me principalmente em Selene Herculano (2006). Para a discussão do conceito de sustentabilidade e justiça ambiental, a principal referência foi Henri Acselrad (2001-2004), com seus estudos sobre a relação entre sustentabilidade e desenvolvimento das cidades.

Também como fonte teórica, recorri a teses, dissertações e acervos sobre Grupos de Pesquisa, dentre outros materiais que contribuíram para a compreensão teórico-conceitual sobre indicadores, Município VerdeAzul e Cidades Sustentáveis.

A pesquisa documental empreendida utilizou-se de fontes primárias. Depois disso, também foi realizada uma pesquisa exploratória sobre os indicadores dos Programas que elegeram a cidade de Sorocaba como uma das melhores do Brasil.

Para incrementar a base empírica, foram empregadas entrevistas semiabertas realizadas com os representantes do governo municipal, lideranças comunitárias e ambientalistas. 
Outro formato (ferramenta virtual do Google Drive) - questionário on-line - foi utilizado para colher a visão da população sorocabana acerca das premiações. Os questionários foram enviados por meio de instituições, tais como universidades, sindicatos e outros grupos sociais.

Procurou-se identificar a percepção dos moradores sobre as premiações, assim como discriminar, de acordo com as zonas de moradias da cidade, como se deu, espacialmente, essa percepção

Minha hipótese é que a elevação da cidade de Sorocaba à categoria de cidade sustentável não expressa o que população local entende por sustentabilidade. Assim, procuro desvendar quais elementos não foram considerados de acordo com a perspectiva das pessoas que vivenciam a cidade. Parece ficar clara a existência de um descompasso entre aquilo que a população considera e as premiações

\section{CONTANDO SOBRE RESULTADOS}

Algumas indagações decorrentes de nossa pesquisa nos fizeram perceber que alguns indicadores mostram muitas informações, muitos números que, apesar de comporem um vasto banco de dados, não oferecem muito além disso. Os dados têm pouco uso ou são, até mesmo, descartados. Perguntamo-nos, então, se isso não seria um sinal de que os indicadores não retratam os anseios do grupo diretamente relacionado com ao objeto da pesquisa.

Nesse sentido, decidimos investigar, em uma cidade real, o sentido da noção de sustentabilidade a partir da vivência. Buscamos, portanto, responder o que é necessário para se ter uma Sorocaba sustentável.

Buscamos conhecer, por meio do questionário, que elementos urbanos integram uma Sorocaba Sustentável, na visão dos sorocabanos.

Perguntamos quais eram os atributos que consideravam sustentáveis ou insustentáveis na cidade e o que era uma Sorocaba sustentável para a população sorocabana. Nossa primeira intenção foi averiguar se a população obteve a informação de que Sorocaba tinha sido premiada em $1^{\circ}$ lugar no Município VerdeAzul (2013) e em 1ํ lugar no Programa Cidade Sustentável (2014). O que se constatou é que uma parcela maior da população não sabia das premiações.

Investigamos, também, os motivos que levaram as pessoas a concordarem com as premiações. Primeiramente, a pergunta foi: "Você concorda com estas premiações atribuídas a Sorocaba, como Cidade Sustentável e Cidade Verde?"' Essa pergunta foi contemplada com $53,1 \%$ que não concordaram com as premiações e 46,9 que concordaram.

Com o intuito de circunscrever os problemas abordados pelos sorocabanos às áreas em que eles moram e, assim, compreender como se articulam os aspectos mencionados nos indicadores e a vivência da população de acordo com as regiões da cidade, levantaram-se as seguintes informações:

Nota-se que, nos discursos dos moradores de Sorocaba, há uma diferença entre as questões apresentadas como relevantes para cada uma das regiões. A Zona Norte, por exemplo, que é a mais populosa, expressa com força a ineficiência do atendimento do transporte público e da saúde e a necessidade de tornar mais presentes programas ambientais. Na área central, a coleta seletiva, os centros culturais e a segurança são os temas apontados. A Zona Leste, palco do embate relativo às Zonas de Chácaras, entende que o Plano Diretor não deve atender a outros interesses, ainda expressam a importância da participação da população nos programas do governo. Na Zona Sul, os moradores enfatizam que, para que cidade tenha o seu desenvolvimento, são importantes campanhas para mudança cultural, pois as pessoas precisam ter mais consciência em relação ao meio ambiente.

Em nossa próxima pergunta, buscamos conhecer quais indicadores a população considerava relevante para a premiação da cidade. Assim, a pergunta feita foi a seguinte: "Vários indicadores foram considerados para que Sorocaba recebesse os prêmios de Cidade Sustentável e Município VerdeAzul. O que mais contribuiu na época?"

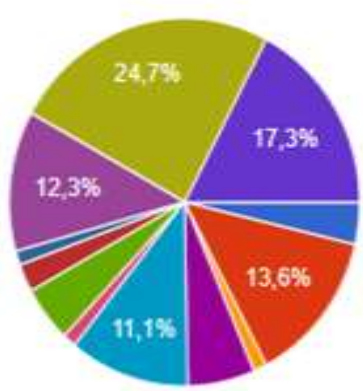

- Patopeçỏo popdar nos programe

- Proteça da Biodiersidast, ajaíd.

(1) Seguranca Pibica satistobia

- Promoço pera a iguadades scail

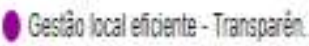

- Proyama de reduczao de consumo.

- Promocio da Sadde e vem estar d.

- Educacáo de vuaidade.
Promoção da cultura: Acervo,

atividades e espaços culturais.

Economia local dinâmica, criativa e sustentável (geraçãa de emprego e.

Mobilidade urbana com reduçãa do uso do carro e ampliação do transp..

Programas locais sobre desastres a.

Arborização urbana e áreas verdes.

Qualidade e gestão das águas. 
É a Arborização Urbana a dimensão que ocupa o maior espaço de contribuição para a premiação (24\%), seguida da Gestão das Águas, que inclui a despoluição do rio Sorocaba $(17,3 \%)$. Segundo nossa análise, esses dados revelam que o olhar do sorocabano volta-se à dimensão ambiental, ao verde, como um indicador importante para a cidade sustentável.

Para nossa proposta investigativa, era necessário, também, conhecer os temas considerados insustentáveis pelos participantes da pesquisa. Para isso, listamos os itens apontados nos índices que visam medir a sustentabilidade de uma cidade, conforme apresentado na parte teórica desta tese. Os itens listados e as pontuações obtidas foram os seguintes:

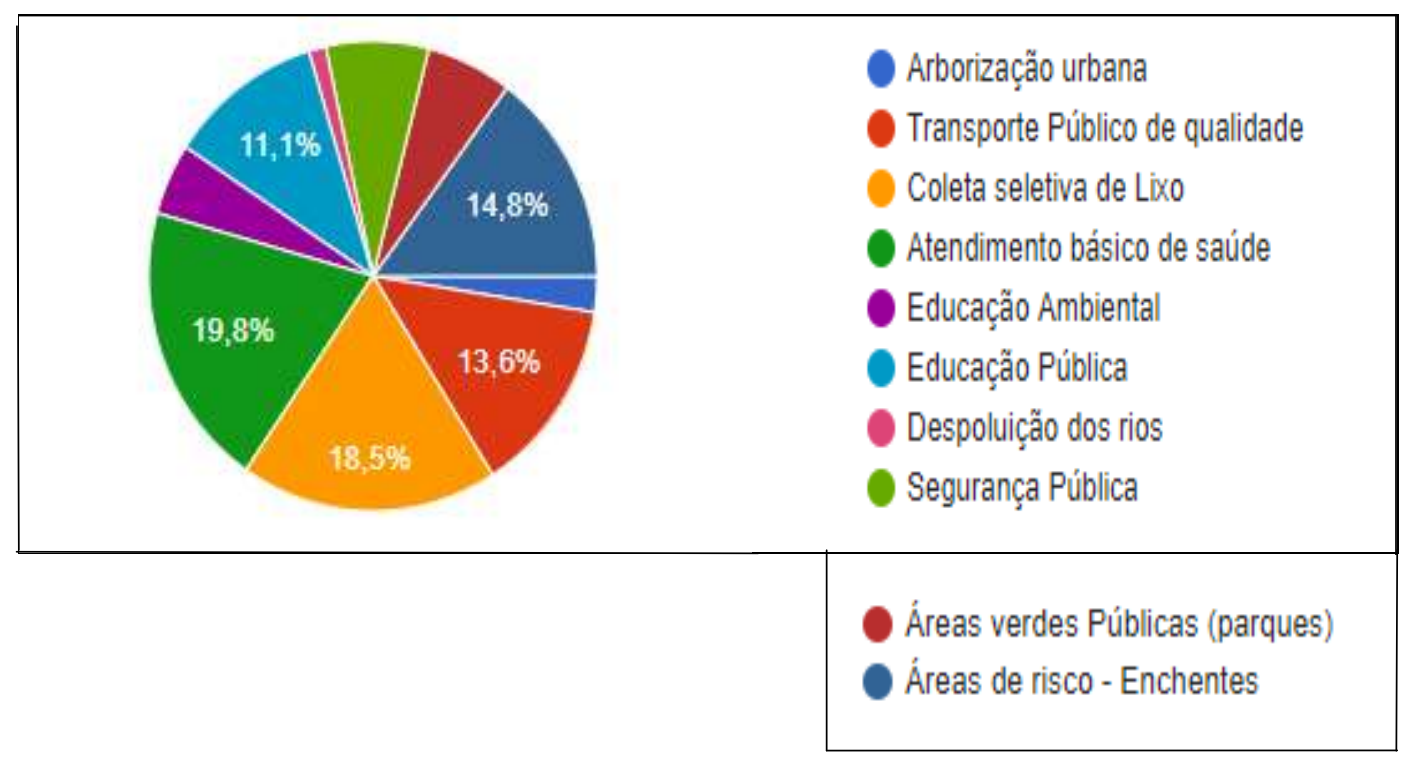

Gráfico 1. Temas insustentáveis em Sorocaba. Elaborado pela autora. Leticia Barroso. out/2017

A insustentabilidade se revela por meio da incapacidade de se ter um bom atendimento à saúde (19,8\%); a deficiência na gestão do lixo (18,5\%) e a existência de áreas de risco e enchentes na cidade $(14,8 \%)$.

Seria uma cidade que não tem bons serviços no atendimento à saúde e de gestão do lixo e sem a preocupação com ações voltadas para prevenção dos desastres ambientais. Isso significa que deverá ser incorporado ao planejamento urbano o conhecimento das vulnerabilidades e dos riscos, a fim de se propor medidas de mitigação e adaptação que aumentem a resiliência urbana em Sorocaba, pois a cidade convive com enchentes, inundações e deslizamentos.

O Programa Cidades Sustentáveis tem inúmeros indicadores que precisam ser trazidos para a população. $\mathrm{E}$, ao examinar os números registrados, é possível identificar as questões que merecem mais atenção, ou seja, mais cuidado na gestão municipal

Os indicadores mostraram que a cidade conta com elementos que contribuem para a pressão urbana. Um deles é a presença crescente de veículos, outro fator são os constantes deslizamentos e enchentes, além da taxa de crescimento geométrico, que é maior que a do Estado de São Paulo.

No que se refere a Educação, apesar da alta nota do IDEB, há questionamento por conta de se tratar de uma medida quantitativa, taxa de pontuação, com caráter cada vez um caráter competitivo e que não expressa a realidade brasileira.

Investigamos os desejos das pessoas, pois, conforme Lefebvre (1991) a cidade não é algo dado, estagnado. A cidade é dinâmica, com as suas mais variadas nuances, é o lugar onde se reproduzem as relações sociais de produção que tem resultado num espaço fragmentado, sem lugares de encontros que oportunizam a ocorrência de trocas.

Seguem os temas que foram mencionados nas entrevistas não induzidas e de livre escolha no que se refere a uma Sorocaba sustentável. Os temas foram elencados na última pergunta do questionário, como relevantes para uma Sorocaba melhor. O gráfico abaixo dá visibilidade a todos os temas citados. 


\section{TEMAS}

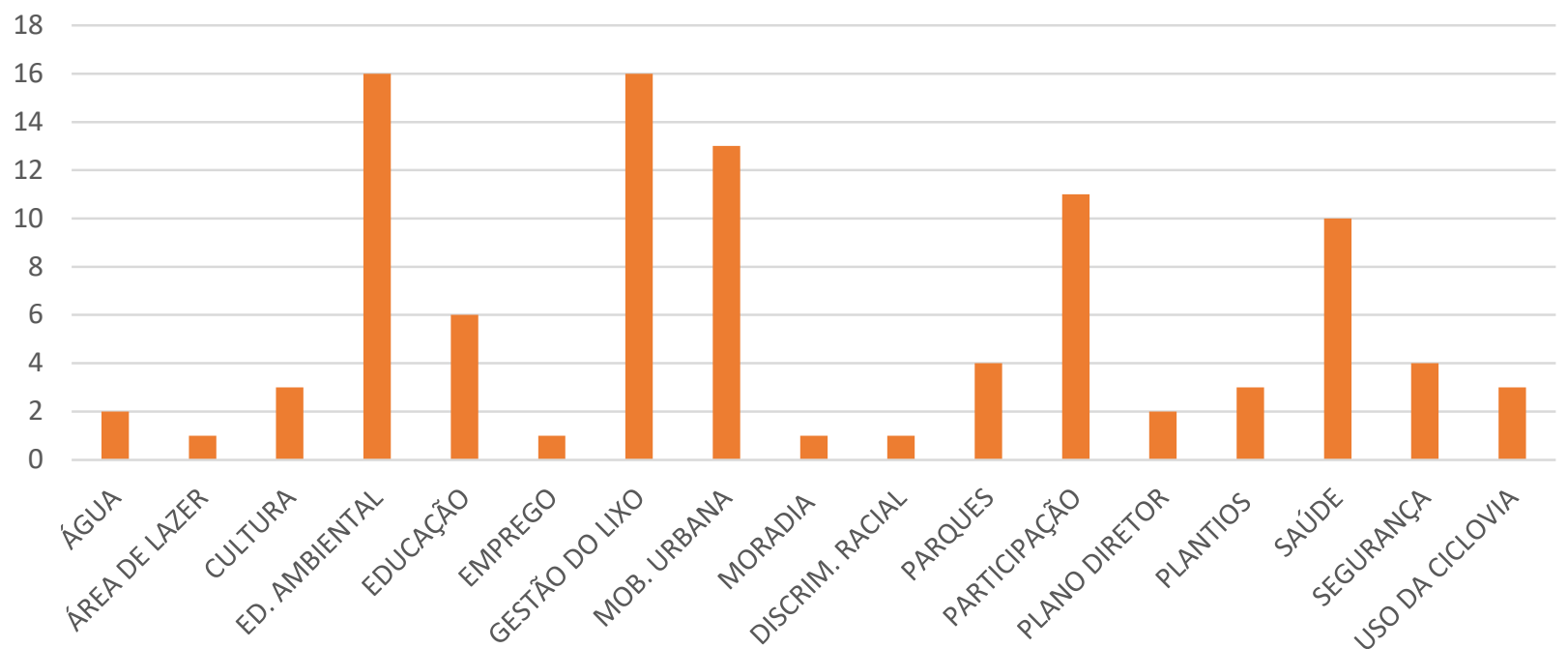

Gráfico 2. Temas apresentados pelos sorocabanos na pesquisa "O que deve ser feito para a cidade fique ainda melhor para se viver". Elaborado por Leticia Barroso. Nov./2017

E, para ajudar nossa análise, elaboramos uma outra tabela unindo as questões temáticas expressas pelo sorocabano. A primeira coluna reúne as respostas das perguntas sobre os temas importantes para se obter a premiação, já a segunda reúne os temas considerados insustentáveis. E, a última, os desejos da população, obtidos ao responderem à questão: "O que deve ser feito para que a cidade fique ainda melhor para viver?" O Quadro abaixo mostra os temas de acordo com as respostas das três últimas perguntas para nossa melhor compreensão.

\begin{tabular}{|c|c|c|c|}
\hline $\mathbf{N}$ & $\begin{array}{l}\text { Vários indicadores foram } \\
\text { considerados para que Sorocaba } \\
\text { recebesse os prêmios de Cidade } \\
\text { Sustentável e Município VerdeAzul. } \\
\text { O que mais contribuiu na época? }\end{array}$ & $\begin{array}{l}\text { Dentre os temas abaixo, } \\
\text { qual você considera o } \\
\text { mais insustentável } \\
\text { atualmente em Sorocaba }\end{array}$ & $\begin{array}{l}\text { O que deve ser feito } \\
\text { para que a cidade } \\
\text { fique ainda melhor } \\
\text { para viver? }\end{array}$ \\
\hline 1 & ARBORIZACCÃO & ATENDIMENTO Ȧ SAUDE & COLETA SELETIVA \\
\hline 2 & QUALDADE E GESTÃO DAS ÁGUAS & COLETA SELETIVA & $\begin{array}{l}\text { EDUCAÇÃO } \\
\text { AMBIENTAL }\end{array}$ \\
\hline 3 & $\begin{array}{l}\text { BIODIVERSIDADE/PARQUES/ÁREAS } \\
\text { VERDES }\end{array}$ & ÁREAS DE RISCO & $\begin{array}{l}\text { MOBILIDADE } \\
\text { URBANA }\end{array}$ \\
\hline 4 & MOBILIDADE URBANA & TRANSPORTE PÚBLICO & PARTICIPAÇÃO \\
\hline 5 & CONSUMO/GESTÃO DO LIXO & EDUCAÇÃO & $\begin{array}{l}\text { ATENDIMENTO A } \\
\text { SAÚDE }\end{array}$ \\
\hline 6 & GESTÃO LOCAL EFICIENTE & SEGURANÇA PÚBLICA & EDUCAÇÃO \\
\hline 7 & EDUCAÇÃO & ÁREAS VERDES & SEGURANÇA \\
\hline 8 & PARTICIPAÇÃO & EDUCAÇÃO AMBIENTAL & $\begin{array}{l}\text { INVESTIMENTO EM } \\
\text { CULTURA }\end{array}$ \\
\hline 9 & PROMOÇÃO DA CULTURA & $\begin{array}{l}\text { DESPOLUIÇÃO DOS } \\
\text { RIOS }\end{array}$ & PARQUES \\
\hline 10 & PROMOÇÃO DA SAÚDE & ARBORIZAÇÃO URBANA & CICLOVIA \\
\hline 11 & SEGURANÇA PÚBLICA & & AREA DE LAZER \\
\hline 12 & ECONOMIA LOCAL & & $\begin{array}{l}\text { ARBORIZAÇÃO } \\
\text { URBANA }\end{array}$ \\
\hline
\end{tabular}

Quadro 1. Organização das respostas: Quadro comparativo das respostas do questionário virtual elaborado pela autora. Leticia Barroso. 10/09/2017 
Ao analisar o quadro acima identificamos que, na perspectiva da população, os atributos que concorreram para elevar a cidade como uma das melhores do Brasil e do Estado de São Paulo se voltam para o verde, quando se referem à Arborização e à Biodiversidade, considerados os atributos mais importantes, aliados ao tema gestão das águas e à proteção da biodiversidade. Desejar a seleção de lixo aponta para uma reflexão de valores e a preocupação com o desperdício, com a finitude dos recursos naturais, levando-o, assim, a compreender a importância do processo participativo na construção do novo.Nessa trilha, é possível caminhar para uma cidade sustentável, o que requer mudanças no estilo de vida: construção de novos valores capazes de romper com a fragmentação e reforçar o coletivo. Esse é um tema que aporta uma mudança cultural.

Poderíamos dizer que o sorocabano entende que a cidade precisa de uma boa gestão do lixo aliada a um processo de Educação Ambiental para garantir uma maior consciência "ecológica".

\section{PENSANDO AÇÕES}

A pesquisa online identificou que os munícipes entrevistados acreditam que a participação da sociedade é fundamental para o alcance da sustentabilidade de Sorocaba, pois é capaz de promover a construção de alianças locais e acesso à informação no que diz respeito ao destino da cidade ao conferir ao cidadão a possibilidade de construir-se como sujeito de direito.

Além disso, as entrevistas com os representantes da prefeitura identificaram a descontinuidade das ações e a redução de investimentos em programas que contribuíram para a premiação da cidade.

Assim, partir de uma sociedade mobilizada, é possível garantir a continuidade dos projetos e ações, até porque a cidade é dinâmica e repleta de mudanças. É também possível garantir que os projetos tenham uma vida atemporal em relação à gestão municipal, ou seja, que ultrapassem o período do governo em vigor e que se mantenham por serem, de fato, relevantes para a cidade. A participação inclui o controle sobre os recursos públicos. Acrescenta-se ainda que, ao estabelecer o envolvimento da população na condução da cidade, a participação possibilita, também, um vínculo maior entre as pessoas e, assim, a possibilidade de ampliar a solidariedade e a cooperação entre elas para se atingir objetivos comuns. Acompanhar os indicadores sociais, ambientais e econômicos poderá desencadear uma mobilização da sociedade para que os investimentos públicos se traduzam numa cidade mais justa.

\subsection{Buscando a capilaridade}

Nesse sentido, unir governo e a sociedade civil favorece que essas instâncias, juntas, conheçam o cenário ambiental, social, cultural, institucional, econômico e assim, de posse de informações, possam acompanhar e avaliar o desenvolvimento dos indicadores e propor novos caminhos para garantir processos de continuidade da participação na construção de uma cidade justa e sustentável.

Como chegar ao sorocabano e favorecer a integração de diversas instituições, organizações que estão sediadas e se movimentam na cidade? Iniciamos com uma contribuição metodológica visando envolver o sorocabano

Circunscrevemos o pensamento do sorocabano sobre a cidade a partir dos locais em que vivem. Apropriamo-nos da divisão por Zonas, num total de sete: Norte, Nordeste, Oeste, Leste, Sul, Sudeste e Sudoeste. Não se trata, aqui, de uma proposta destacada, mas de pensar alternativas para 0 desenvolvimento de uma cidade sustentável, com uma estrutura participativa diferenciada.

O primeiro passo seria mapear as organizações governamentais e não governamentais existentes nessas regiões. Isso significa que cada Núcleo Urbano seria constituído pelas respectivas organizações existentes nessas regiões. Identificadas as primeiras organizações, seus representantes se reuniriam com os gestores públicos, para o início de um processo para o monitoramento do desenvolvimento sustentável da cidade.

Seria então a constituição de 7 (sete) Núcleos Urbanos - NU. Para tanto, deverá ocorrer a sensibilização por parte do Poder Público, junto aos gestores, de forma a mobilizar a população local. O passo seguinte seria a criação do Núcleo Gestor Urbano, constituído de representantes dos Núcleos Urbanos, cuja atribuição seria organizar e reunir as discussões setoriais. . De cada Núcleo Urbano, representantes deveriam ser destacados para compor o Núcleo Gestor Urbano, que deverá ter a atribuição de integrar as proposições dos sete setores. Propõem-se reuniões trimestrais, que denominaremos como Reuniões de Integração, com o objetivo de expôr as discussões setoriais, trocar informações com os outros Núcleos. E, de modo complementar, duas Plenárias, semestrais, para os debates e encaminhamentos das definições.

Essas reuniões seriam, também, um espaço de interlocução entre os integrantes de cada Núcleo Urbano.Tais direcionamentos iniciais possibilitariam uma divisão por setores e poderiam ser modificados conforme o desenvolvimento do processo

Assim, as organizações existentes e que atuam em diversas áreas seriam agrupadas, em uma forma de favorecer a diversidade de olhares a partir de diferentes dimensões. 


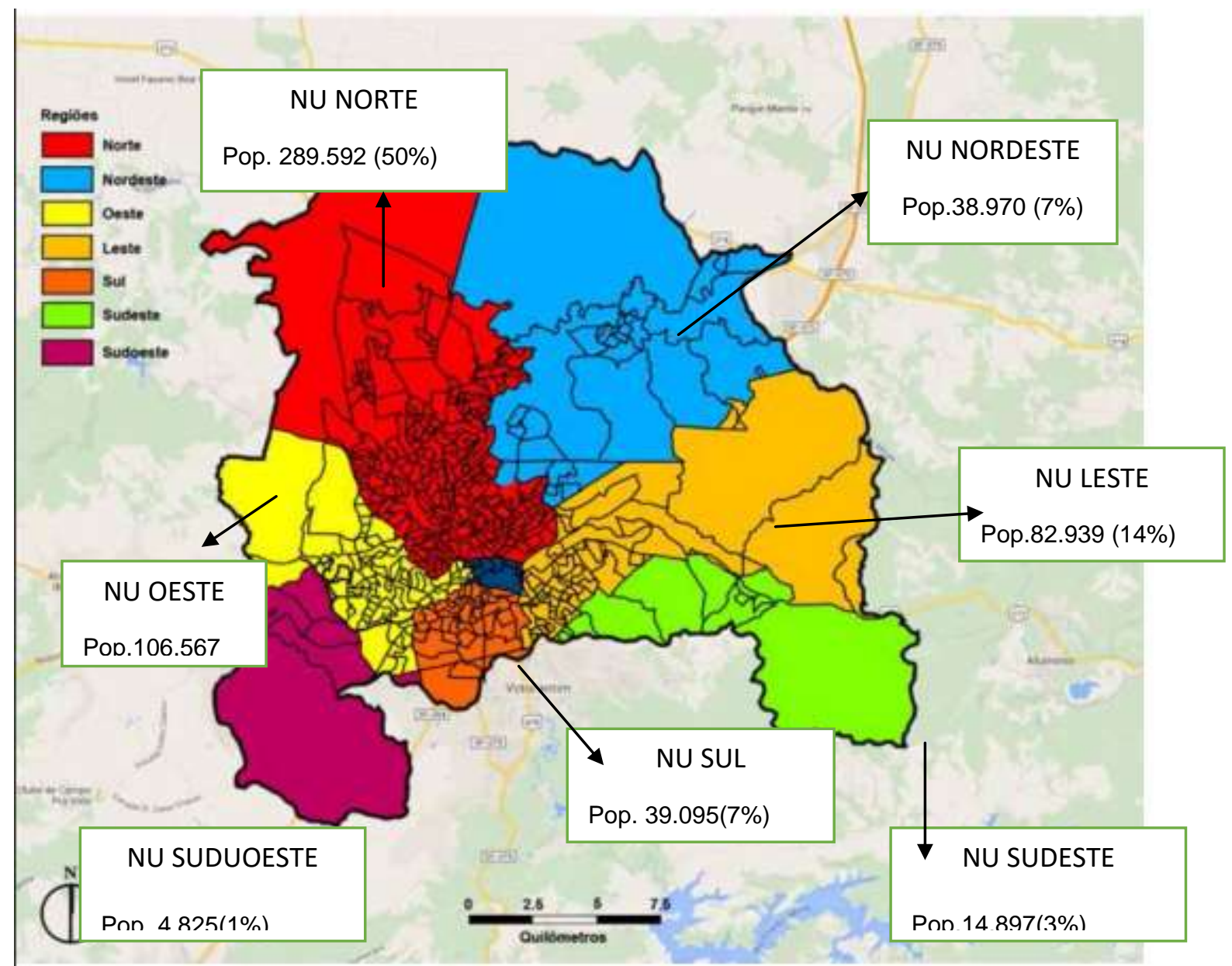

Mapa 1. Sorocaba e os setores. Fonte: PDA.2010

Os dados acima referem-se à população de 2010 (IBGE). Cada Núcleo constituído de representantes governamentais e não governamentais tomaria ciência de todos os dados da cidade.

Indicaremos, a seguir, quais organizações poderiam compor o Núcleo Urbano. Isso significa que teríamos sete Núcleos Urbanos, constituídos de organizações governamentais e não-governamentais.

Instituições diversas poderiam ocupar o lugar social de disseminadoras de novas formas de ser e estar na cidade, ajudando as comunidades a repensar seu papel nos modos de vivenciar as cidades. Sabemos que muitas outras instituições poderiam ser agregadas no desenvolvimento de avaliação da cidade, a depender das necessidades sociais e históricas de cada comunidade.

As escolas, por exemplo, deveriam ser privilegiadas como espaços de interlocução, por abrangerem o universo educativo e poderem contribuir com toda a comunidade escolar. Alunos, famílias, moradores e trabalhadores do entorno e os próprios professores e funcionários poderiam se envolver e construir uma rede de informações.

Representantes da Associação de Moradores e lideranças comunitárias também seriam capazes de promover uma organização, visto que têm a capacidade de mobilizar as pessoas, por meio do conhecimento dos problemas do bairro, da cidade e da integração com outras diversas organizações locais Agentes de Saúde, em específico as Agentes Comunitários do Programa da Saúde de Família ${ }^{4}$ são importantes por conviverem com os problemas locais e estarem muito próximas às familías, mais especificamente nas casas das pessoas, o que possibilita dialogar e buscar informações sobre o local em que elas vivem.

\footnotetext{
${ }^{4}$ O Programa de Agentes Comunitários de Saúde (PACS) teve início no fim da década de 80 como uma iniciativa de algumas áreas do Brasil para buscar alternativas para melhorar as condições de saúde de suas comunidades. São trabalhadores do Sistema Único de Saúde que atuam com a comunidade da área, do bairro, da cidade ou da região rural para facilitar o acesso da população à saúde e prevenir doenças. O ACS deve visitar regularmente residências e fazer registros da população, em relação a documentos básicos para o acesso aos serviços de saúde e em relação aos possíveis problemas de saúde identificados na residência. Assim, o ACS deve orientar pessoas em relação à sua saúde e encaminhá-las ao posto de saúde ou a outros locais de atendimento sempre que necessário.
} 
As medidas também poderiam envolver outras instituições: Organização Cultural, pela importância da linguagem da arte no processo de envolver as pessoas; Igrejas e grupos de jovens, que podem contribuir com uma nova linguagem para entender a cidade; Sindicatos, pela importância de agregar pessoas envolvidas com a questão dos conflitos urbanos; Universidades, pela capacidade de contribuir com pesquisas e análises e pela possibilidade de traduzir os indicadores em uma linguagem acessível à população; Empresas Privadas; Associações de Seviços e Entidades Filantrópicas.

\subsection{Organizando os indicadores e os temas}

Para embasar e discutir a caracterização apresentada, recorreu-se às experiências de grandes cidades brasileiras, e ao trabalho intitulado "índice de sustentabilidade urbana", de Tânia Moreira Braga (2003), realizado na região do Vale do Aço (MG).

De posse dessa informação, apoiamo-nos nos seguintes índices que podem colaborar para o planejamento local, composto por quatro temas: i) qualidade do sistema ambiental local; ii) qualidade de vida humana; iii) pressão antrópica; iv) capacidade política e institucional.

No quadro a seguir, inserimos indicadores já adotados nos dois Programas - PMVA e PCS - aos índices de qualidade de vida humana, pressão antrópica e capacidade político-institucional. Mas, para compor a tabela, orientamo-nos pelos temas apresentados pelo sorocabano, ou seja, os considerados importantes para que a cidade fique ainda melhor. A partir desses temas, definimos sete agrupamentos temáticos Saúde; Trânsito e Tráfego; Cobertura Vegetal, Saneamento Ambiental; Educação, Segurança e Participação - que compõem o índice Qualidade de Vida. Perseguindo a sustentabilidade e a importância da inclusão de todos, nosso primeiro olhar é para identificar o acesso, por parte de toda a população, aos serviços urbanos.

\begin{tabular}{|c|c|c|}
\hline ÍNDICES TEMÁTICOS & INDICADORES & COMPOSIÇÃO DOS INDICADORES \\
\hline \multirow{28}{*}{ Qualidade de vida } & \multirow[b]{2}{*}{ Condições de Vida } & Índice de Longevidade - IDH \\
\hline & & Índice de Educação - IDH \\
\hline & \multirow{10}{*}{ Saúde } & Mortalidade de aparelhos respiratórios \\
\hline & & Índice de Mortalidade Infantil \\
\hline & & Índice de Leitos hospitalares \\
\hline & & Índice de Mortalidade Materna \\
\hline & & Unidades Básicas de Saúde \\
\hline & & Pessoas infectadas por Dengue \\
\hline & & Doenças de Veiculação Hídrica \\
\hline & & Mortalidade do Aparelho Circulatório \\
\hline & & Desnutrição ao Nascer \\
\hline & & Baixo Peso ao Nascer \\
\hline & \multirow{7}{*}{ Trânsito e Tráfego } & Índice de Atropelamentos \\
\hline & & Índice de Acidentes de Trânsito \\
\hline & & Índices de Mortos no Trânsito \\
\hline & & Índices de Mortes por Atropelamento \\
\hline & & Ônibus com Acessibilidade \\
\hline & & Ciclovias \\
\hline & & Corredores Exclusivos de Ônibus \\
\hline & \multirow{7}{*}{ Cobertura Vegetal } & Arborização Urbana \\
\hline & & Vegetação Mata Ciliar \\
\hline & & Reservas de Áreas Protegidas \\
\hline & & Área Verde por Habitante \\
\hline & & Área Desmatada \\
\hline & & Queimadas Urbanas \\
\hline & & Educação Ambiental \\
\hline & & Índice de Abastecimento de Água \\
\hline & & Índice de Consumo de Água \\
\hline
\end{tabular}




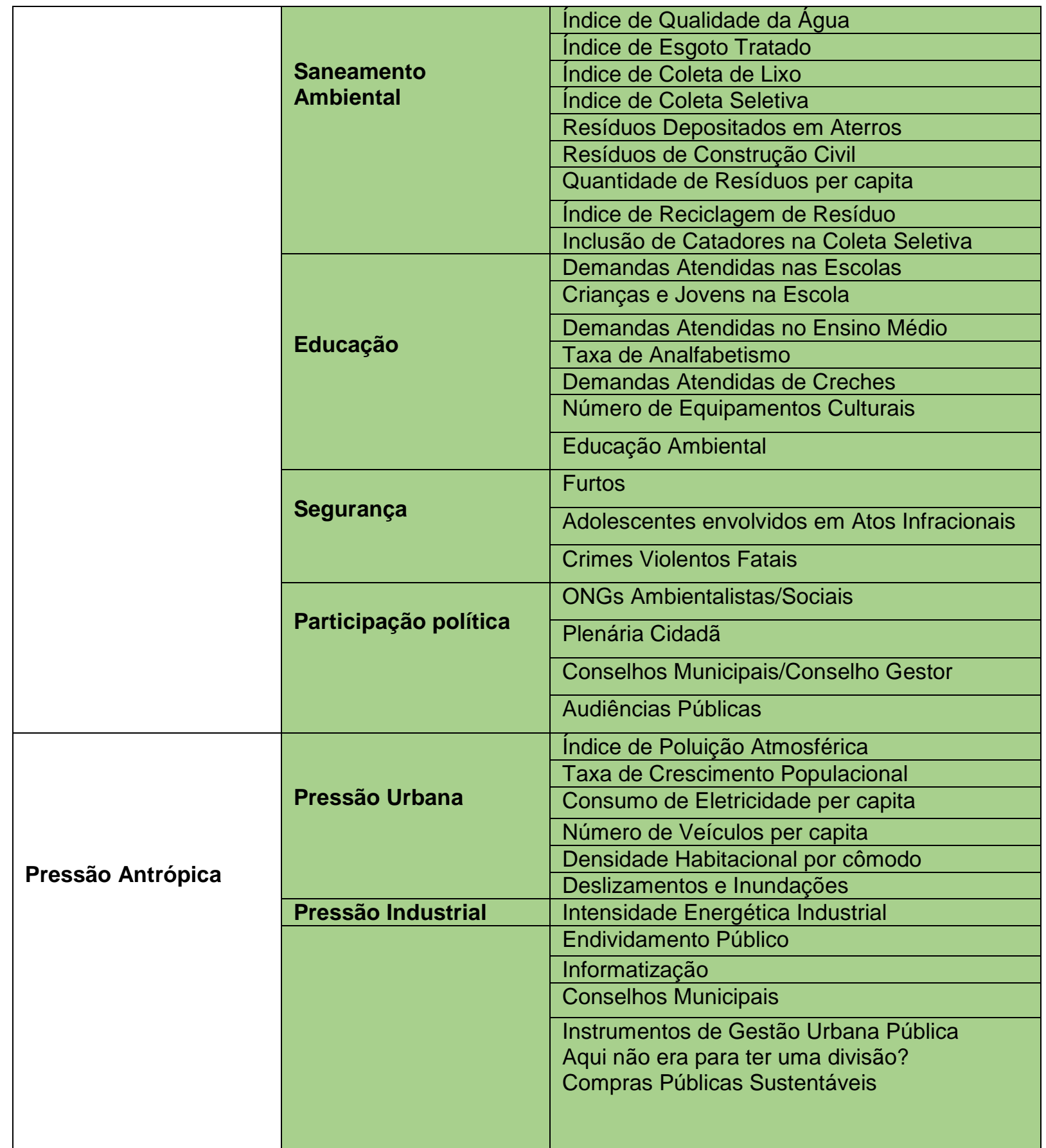

Quadro 2.Fonte: BRAGA, Tania Moreira. Índices de sustentabilidade municipal: o desafio de mensurar. Tânia Moreira Braga. 2003. pg.12. Adaptado pela autora. Leticia Barroso. Out/2017.

A grande contribuição para a tabela acima é exatamente a inclusão dos temas mais intensamente mencionados nas entrevistas realizadas. Esses foram os temas apontados para se ter uma Sorocaba melhor de se viver. Somente a partir da seleção desses temas ocorre a proposição dos indicadores constantes nos dois Programas. Os indicadores abordados devem ser dispostos aos participantes no sentido de verificar se atendem ou não aos critérios em análise.

Finalizo propondo uma dimensão que considero de suma importância, que é a Felicidade, que trata da satisfação com os serviços públicos e com a cidade em que se vive e que, de certa forma, dialoga com os indicadores do Felicidade Interna Bruta - FIB. A Felicidade poderá ser creditada aos bons indicadores, àqueles que respondem à satisfação da população.

No entanto, perguntas que versam sobre o que é ser feliz em uma cidade e sobre o que é uma cidade feliz permitem uma série de respostas subjetivas. Mesmo assim, constatamos que há inúmeros modelos 
estatísticos desenvolvidos para analisar a qualidade de vida urbana, embora todos sejam exclusivamente voltados a indicadores quantitativos. Por isso, cabe pensar no aperfeiçoamento do tema "Felicidade", desmembrá-lo em novas necessidades e anseios humanos, para dar conta de sua aplicabilidade em termos reais.

Isso significa a possibilidade de construir indicadores que possam catalisar mudanças, novos hábitos e mobilizar as pessoas visando ao bem-estar coletivo e ao desenvolvimento sustentável, tendo como base a inovação e a construção de novos olhares e soluções, com vistas à satisfação por parte dos indivíduos. Aliás, vimos que o sorocabano quer mudança de hábitos.

Assim, novas formas de mensurar a vida na cidade podem se dar a partir do FIB, que possibilita um olhar diferente para as nove dimensões que nos rodeiam: bem-estar psicológico; saúde; uso do tempo; educação; diversidade cultural, resilência; boa governança; vitalidade comunitária; diversidade ecológica; padrões de vida.

Iniciamos pela saúde, o tema considerado o mais insustentável, que deve ser questionado não como somente pela precariedade do atendimento, mas voltar para a existência de uma medicina preventiva. $\mathrm{O}$ FIB também mensura como é utilizado o tempo. Verifica, por exemplo, se o uso do tempo é gerido de maneira equilibrada: diariamente, em que as pessoas utilizam seu tempo? Quantas horas são dedicadas a trabalho, estudo, sono, lazer, família, religião? Dessa forma, pode-se observar se o tempo é utilizado para o alcance da satisfação ou muito mais para o trabalho, por exemplo. $O$ tempo também se vincula à acessibilidade, à facilidade de ir e vir, pois a crise de mobilidade nem sempre permite descortinar outros espaços, espaços de felicidade. O FIB relaciona a participação com a vitalidade comunitária, pois ela, inserida em um processo, desperta valores como cooperação, solidariedade necessários para que as comunidades sejam equilibradas e felizes.

O pilar do FIB é a Educação, pois a partir dela os indivíduos têm a possibilidade de atingir e de exercer seu pleno potencial, tanto individual como coletivo. Aposta-se na arte, nos valores educacionais. Além disso, também é importante o respeito ao outro, saber lidar com a diferença. Ou seja, a diversidade cultural, sob o ponto de vista da ideologia do FIB, é fundamental para o bem-estar e o alcance da felicidade.

Vale ressaltar a importância, para o debate sobre felicidade, do respeito à natureza, de entender e lidar com a finitude dos recursos e, a partir disso, fazer advir novos hábitos. É necessário ter consciência das limitações e da perenidade da vida. $O$ acesso às áreas verdes, parques e praças permite que o homem se torne responsável pelo espaço público e que se reconecte com espaços desarticulados, de modo a ressignificá-los e a criar conexões com a cidade.

Para além destes elementos que trazem satisfação, não é possível deixar de mensurar a renda familiar e individual, a segurança nas finanças e a qualidade habitacional.

O FIB nos obriga a perguntar qual a cidade que queremos ter e qual o tipo de vida que queremos ter. O FIB relaciona o otimismo de cada cidadão à sua forma de vida. Propõe, assim, análise de autoestima, de nível de stress e de espiritualidade. Resgatar a autoestima das pessoas é também resgatar o lugar em que se vive, a cidade.

Nesse processo, inclui não só o bem-estar da população, mas também a felicidade e as dimensões que se afinam a ela quando incorporadas no cotidiano das pessoas. É preciso dizer, também, que, diante das contradições urbanas, a emancipação do desejo é uma tarefa difícil e que pode levar a muitos anos de luta. Mas, como escreveu Bertolt Brecht (s/d, apud, HARVEY, 1996, p. 439):

Muitas coisas são necessárias para mudar o mundo: raiva e tenacidade, ciência e indignação, a iniciativa rápida, a reflexão longa, a paciência fria e a infinita perseverança, a compreensão do caso particular e a compreensão do conjunto, apenas as lições da realidade podem nos ensinar como transformar a realidade. 


\section{CONSIDERAÇÕES FINAIS}

Apenas recentemente a busca da sustentabilidade se apresentou como uma alternativa possível e necessária para alcançar o objetivo de construir uma cidade ideal. Em nossa investigação a respeito da sustentabilidade, julgamos necessário agregar o conceito de resiliência, pois ele introduz uma nova abordagem para se lidar com a gestão das cidades ao torná-las menos vulneráveis a partir do desenvolvimento de capacidades adaptativas a eventos adversos e ameaças naturais.

Entendemos que pensar a cidade sustentável trata-se, sim, da construção de um novo olhar do espaço urbano, de um conjunto de práticas, instrumentos e mecanismos que possam garantir, de forma contínua e consciente, respostas aos desafios constantes e complexos, mediante a apropriação da cidade pelo conjunto da sociedade.

Constata-se, portanto, que o ajuste de políticas ambientais no município de Sorocaba não atenuou outros problemas da cidade e que a questão ambiental ainda não se constitui como uma prioridade dentro da agenda municipal.

Mas o discurso alardeado pela gestão, alicerçada nas premiações recebidas, é de que a cidade é sustentável, visto se tratar de uma cidade verde. É como se apenas isso assegurasse o bem-estar social, já mostrou não ser verdade. Outra questão importante de ser ressaltada é que é ingênuo acreditar que as estatísticas possam revelar as contradições decorrentes da reprodução da sociedade no espaço.

Procedemos à investigação para compreender se de fato os moradores dessa cidade se apropriaram das referidas premiações e se sentiam-se contemplados pelas políticas públicas locais. A pergunta que nos norteou foi se estes prêmios refletiram, de alguma forma, no bem-estar, no cotidiano da população local. $O$ fato de que mais da metade da população desconhecia as premiações do município de Sorocaba, nos remeteu ao importante e fundamental elemento, que é a participação da população na construção de uma cidade sustentável.

Iniciamos, então, nossa análise de como os índices presentes nas premiações foram sentidos por alguns munícipes e se, de fato, a cidade era vista como sustentável para eles, assim como tinha sido para os Programas a que elas tinham sido vinculadas.

Isto posto, retomo a hipótese principal da pesquisa, qual seja, a de que a cidade de Sorocaba, que foi elevada à categoria de cidade sustentável, por meio dos programas anteriormente citados, não dialoga com a população local e que, portanto, seria possível desvendar outros elementos que não haviam sido considerados pela óptica dos programas.

Tanto o PSC como o PMVA contaram com expressiva divulgação mediante a existência de um Ranking que oferece uma visibilidade inédita ao exibir o desempenho de bons indicadores dos municípios e suas pontuações. Por outro lado, identificamos que o fato de as cidades se encontrarem em boas posições do ranking não significa que estão dentro do desejado pela população e que o fato de se atingir as metas não resultou na eliminação dos conflitos urbanos.

Salientamos que, em relação ao PMVA e ao PCS, esses programas carecem de uma melhor conceituação, pois têm como foco somente os resultados e dados obtidos, e com relativa dificuldade de aferir, ou melhor, comprovar as informações obtidas pelos municípios.

Em nosso entender, os indicadores deveriam ser feitos de forma integrada, medindo as dimensões sociais e ambientais, que são constituintes do desenvolvimento sustentável

Para nós, portanto, um dos destaques de nossa pesquisa foi exatamente a capacidade de transitar entre os dados oficiais da cidade - generalistas e, por isso mesmo, capazes de promover invisibilidades e apagamentos de questões de suma importância para a efetivação de uma cidade realmente sustentável - e os dados de cada uma das regiões da cidade - que, mais particularizados, permitiram um contraste que lançasse luz a pontos que alguns teimam em manter na sombra.

Por meio desses contrastes, por exemplo, notamos as diferenças de abordagem dada pelos moradores de cada uma das regiões aos indicadores de sustentabilidade. É a Arborização Urbana a dimensão que ocupa o maior espaço de contribuição para a premiação, seguido da gestão das águas, que inclui a despoluição do rio Sorocaba. Nossa análise é que essas dimensões revelam que o olhar do sorocabano volta-se para dimensão ambiental, ao verde, como um indicador importante para a cidade sustentável. A proteção dos recursos naturais e a biodiversidade são atribuídas a esse item.

A insustentabilidade se revela por meio da incapacidade de se ter um bom atendimento à saúde e por meio da deficiente gestão do lixo e da existência de áreas de risco e enchentes na cidade. Mesmo que o índice do Eixo Saúde do Programa Cidades Sustentáveis apresente bons índices, isso não se reflete em um bom 
atendimento no cotidiano do Sorocaba. Isso nos faz refletir que os bons índices ambientais não dialogam com o atendimento da saúde, que é considerado precário pelo sorocabano.

Observa-se, então, um descompasso entre o que se mede nos Programas e o desejo por parte da população. A Sorocaba sustentável requer uma cidade que funcione bem na prestação de serviços e que se organize como uma cidade resiliente. Anunciam os moradores que a cidade tem que ser aquela que realize uma boa gestão da coleta de seletiva de lixo, uma boa mobilidade urbana, e uma cidade nutrida por processos educativos, a educação ambiental e que se estabeleça um processo participativo. Quando se é apontada a Educação Ambiental, aponta-se também as campanhas educativas com conteúdo para o consumo consciente e outras questões associadas ao cuidado com a cidade empurrando o sorocabano para a esteira da preocupação com o desperdício, com a finitude dos recursos naturais, o consumismo levando-o a compreensão da importância do processo participativo na construção do novo.

Uma cidade melhor para se viver deve propiciar um caminho que cultive novos valores, descortine novos hábitos para permearem o cotidiano e possibilite vivências que tornem clara a importância do coletivo. Nessa trilha, é possível caminhar para uma cidade sustentável, o que requer mudanças no estilo de vida, rompendo com a fragmentação e reforçando o coletivo. Este é um tema que aporta uma mudança cultural.

Reconheci, nos discursos dos entrevistados, que muitos deles acreditam que a cultura é pensada somente sob a ótica de eventos e shows, há que rever a política cultural da cidade. Ouvi também que a insegurança está presente na cidade, o que obriga intervenções para maior controle das ruas. Nota-se também, a diversidade de problemas, de diferentes dimensões, abordada pelas lideranças entrevistadas. É preciso ouvir essas vozes diferentes.

Isso posto, por estas e por outras dimensões, é que nossa hipótese se confirma: uma "cidade sustentável" ou uma "cidade verde" não pode conviver com inseguranças no âmbito socioambiental, insegurança no atendimento à saúde, dificuldades de acessibilidade e outras dificuldades várias que impactam a vida do cidadão, que não consegue se apropriar do espaço público e viver de fato a cidade que o abriga.

Percebeu-se, portanto, que a cidade sustentável não ocorre no vazio, nos limites de muros, concretos e avenidas - nem mesmo quando eles são quebrados pelo verde alardeado em manifestações acríticas daqueles que compram como verdade absoluta o discurso das "cidades verdes". A cidade sustentável existe no entrelaçamento entre condições ambientais, econômicas, sociais e culturais nas quais os sujeitos se inserem.

Do nosso ponto de vista, é necessário que se estabeleça o exercício do diálogo entre os diferentes setores da sociedade, para pensar a cidade sustentável, tendo como ingrediente a colaboração, o comprometimento, e o monitoramento do desenvolvimento da cidade. Nesse sentido, apropriamo-nos deste entendimento e assumimos neste trabalho a importância de se abrir para a descentralização espacial e de criar espaços de interlocução entre as diversas organizações governamentais e não governamentais, a necessidade de conhecer a evolução dos indicadores e não meramente a soma dos aspectos, até mesmo para se pensar a prioridade dos investimentos. É também possível garantir que os projetos tenham uma vida atemporal em relação à gestão municipal, ou seja, que ultrapassem o período do governo em vigor e que se mantenham por serem, de fato, relevantes para a cidade.

Para tanto, os Núcleos Urbanos - NU foram distribuídos em sete setores, os quais apropriaram-se de temas que foram mais intensamente mencionados pela população. Não se trata de um modelo fechado, uma vez que ele poderá ser modificado, ampliado e transformado conforme o desenvolvimento do processo. Além disso, há que se pensar em planos de comunicação entre os participantes e entre estes com a população, criando-se redes de informação e acesso a todos.

A investigação aponta para a importância de que o pensamento urbano deve ser não mais somente de uma pessoa ou de um grupo, mas um caminho a ser trilhado por muitos, por todos. Que, mesmo com tensões e interesses conflitantes, seja possível produzir valores e ideias. Isto posto, cria-se a possibilidade de entrar no campo do devir. O devir não é o caminho para se atingir uma forma especifica de cidade, mas uma forma de encontrar projetos inovadores. 


\section{REFERÊNCIA BIBLIOGRÁFICA}

ACSELRAD, Henri. A duração das cidades. Sustentabilidade e risco nas políticas públicas, Rio de Janeiro: DP\&A Editora, 2001. 238 p.

BAUMAN, Zigmunt. Identidade. Rio de Janeiro: Jorge Zahar Editor, 2005. 110 p.

BELLEN, H.M.Van. Indicadores de sustentabilidade: uma análise comparativa. 2.ed. Rio de Janeiro: FGV Editora. 2006. 256 p.

BRAGA, Tania Moreira. Índices de sustentabilidade municipal: o desafio de mensurar. Belo Horizonte: UFMG/Cedeplar, 2003. 22p. (Texto para discussão ; 225)

CHOAY, Françoise. O urbanismo: Utopias e Realidades uma antologia. 5 ed. São Paulo: Editora Perspectiva S.A., 2003. 350 p.

HARVEY, David. Cidades Rebeldes. São Paulo: Martins Fontes-selo Martin, 2014. Espaços de Esperança. São Paulo: Edições Loyola, 2014.

LEFĖBVRE, Henri. O direito à cidade. Trad. Rubens Eduardo Frias.5 ed. São Paulo: Centauro, 2001. 146 p.

.A vida cotidiana no mundo moderno. São Paulo: Editora Ática, 1991. 216 p.

A revolução urbana. Belo Horizonte: Editora da UFMG, 2008.178 p.

$\overline{\text { JACOBS}}$, Jane. Morte e vida de grandes cidades. $3^{\mathrm{a}}$ ed. Editora WMF Martins Fontes, São Paulo, 2011.

HERCULANO, Selene. Em busca da boa sociedade. Niterói: EdUFF, 2006. 426 p

ROGERS, Richard. Cidades para um pequeno planeta. $2^{2}$ ed. São Paulo: Saraiva, 2016.

ROLNIK, Raquel. O que é cidade. 4 ed.SãoPaulo:Editora Brasiliense. 2009. 100 p.( Coleção Primeiros

Passos).

SACHS, Ignacy. Desenvolvimento includente, sustentável, sustentado. Rio de Janeiro: Garamond

Universitária, 2004 